\title{
Fiscal policy and the term premium in real interest rate differentials
}

\author{
T. J. FLAVIN and M. G. LIMOSANI* \\ Dept of Economics, NUI Maynooth, Co.Kildare, Republic of Ireland, *Universita \\ diMessina, Italy and $\$$ Dept of Economics and Related Studies, University of York, \\ York, Y01 5DD, UK
}

The paper seeks to identify the source of the risk premium in real interest rate differentials across European countries. In particular, the link between real interest rate differentials existing between various European countries and Germany, and domestic fiscal policy as proxied by the Debt/GDP ratios in these countries is examined. Results provide strong evidence that this variable exerts a significant influence on the determination of both the level and the volatility of the differential for both long-term and short-term interest rates. This is a noteworthy result bearing in mind the Maastricht criteria for European Monetary Union and the importance attached to convergence of Debt/GDP ratios.

\section{INTR ODUCTION}

The risk premium seems to be the main factor accounting for real interest rate differentials across European countries (Frankel and MacArthur, 1988; Limosani and Wickens, 1998). Despite the consensus on the importance of this premium in the determination of interest differentials, there is little agreement about the source of the risk premium. In fact, this issue has rarely been addressed in the empirical literature. This paper takes a first step in filling this void by investigating the relationship between the risk premium and the behaviour of macroeconomic factors. In particular, the link between the real interest rate differential and domestic fiscal policy is examined, as proxied by the Debt/GDP ratio, in a model which allows macroeconomic factors to exert an influence on both the conditional mean and variance of the process. ${ }^{1}$

Using both long-term and short-term interest rates, we find strong evidence that the Debt/GDP ratio is a significant and important determinant of both first- and secondorder moments of the process. This result has important policy implications in that a convergence of ratios would seem to be necessary in order to eliminate real interest rate differentials across countries.
This paper is structured as follows. Section II presents the theoretical background which helps us to identify the relevant macroeconomic variables. Section III describes the data and discusses the empirical model while Section IV presents the results of the estimation. Finally, Section V contains concluding remarks.

\section{THEOR ETICAL BACKGR OUND}

Portfolio theory provides a loose rationale for modelling the demand for an asset as a function of the structure of expected yield (Tobin, 1958; 1982; Markowitz, 1952; Constantinides and Malliaris, 1995).

The demand function for government bonds in real terms can be expressed as

$$
\left(\frac{B^{d}}{p}\right)_{t}=f\left[\left(r-r^{*}\right)_{t},\left(\frac{Y}{p}\right)_{t},\left(\frac{W}{p}\right)_{t}, \sigma_{t}\right]
$$

where $B^{d} / p$ is the real demand for bonds, $(r-r *)$ is the real ex-ante excess return, $Y$ is nominal income, taken as an indicator of human capital although it is an incomplete and imperfect one; $W$ is financial wealth;

${ }^{1}$ This exercise is conducted as a partial analysis, seeking to highlight the potential link between the real interest rate differential and Debt/ GDP ratios and does not claim to represent a complete characterization of the differential. 
$\sigma$ is the conditional variance representing the underlying risk of the asset arising from the uncertainty of asset returns.

Expressing the demand for government bonds as a proportion of nominal GDP, Equation 1 can be written as

$$
b_{t}=f\left[\left(r-r^{*}\right)_{t}, w_{t}, \sigma_{t}\right]
$$

where the lower case letters, $b$ and $w$, denote that the corresponding upper case variables have been divided by nominal income.

The supply of government bonds in the economy arises from the need to finance the public deficit and from open market operations by the relevant fiscal authority, with the former being the more dominant factor. The government budget constraint can be written as

$$
G_{t}-T_{t}+i_{t} B_{t-1}=\Delta B_{t}+\Delta M_{t}
$$

where $G_{t}$ is government expenditure, $T_{t}$ is government revenue from taxes; $B_{t}$ is government debt at the end of the period, $i_{t}$ is the interest rate on government debt, typically represented by a long-term bond yield. Deflating Equation 3 by nominal GDP $(Y)$ and re-arranging we obtain

$$
d_{t}+\rho_{t} b_{t-1}=\Delta b_{t}
$$

where $d_{t}=g_{t}-\dot{p}+\Delta m-(\dot{p}+g)$ is the government primary deficit expressed as proportion of nominal GDP and $\rho_{t}=i-\dot{p}-g$, is the ex-post interest rate adjusted for real output growth $(g)$.

The equilibrium condition in the bond market can be written as

$$
f\left[\left(r-r^{*}\right)_{t}, w_{t}, \sigma_{t}, b_{t-1}\right]=\Delta b_{t}
$$

This condition can be interpreted as an implicit function of the form:

$$
F\left[\left(r-r^{*}\right)_{t}, w_{t}, \sigma_{t}, b_{t-1}, \Delta b_{t}\right]=0
$$

which can be solved as

$$
\left(r-r^{*}\right)_{t}=\varphi\left(w_{t}, \sigma_{t}, b_{t-1}, \Delta b_{t}\right)
$$

Assuming that the ratio, $(W / Y)=w$ changes very slowly and that it is approximately one, Equation 7 expresses a relationship between the real ex-ante excess return, the debt/GDP ratio and the conditional variance. In the steady state $\Delta b_{t}=0$, then Equation 7 becomes

$$
\left(r-r^{*}\right)_{t}=\varphi\left(\sigma_{t}, b_{t-1}\right)
$$

This theoretical framework suggests that the level of Debt/ GDP represents the long-run effect of this variable on the real ex-ante excess return, while the first difference captures the effects of the short-run dynamics due to the need to finance the deficit. Asset pricing models, however, fail to provide any guide to the sources of time variation in the conditional variance. Tobin (1982) observes:

Asset demand functions cannot be expected to be stable in the face of significant variations in the economic envir- onment. The variances and covariances of returns on several assets reflect probability distribution of more fundamental shocks to the economy. These are exogenous shocks in technology, tastes and foreign economies as well as in government policies (Tobin, 1982, p. 186).

Different approaches to modelling the conditional variance have been suggested in the empirical literature on international finance. The first approach would be to consider a constant variance following Frankel (1982). An alternative approach could be to assume that the conditional variance varies over time using a $(\mathrm{G}) \mathrm{ARCH}(\mathrm{M})$ model introduced by Engle (1982) and Bollerslev (1986). A final approach is to allow the conditional variance to be influenced by time varying macroeconomic factors like Clare et al. (1993).

In this paper we model both the conditional mean and the conditional volatility of the real ex-ante excess return. In particular, we estimate the mean equation (Equation 7), with $\sigma$ represented by the square root of the conditional variance of the process. In modelling the conditional variance the third approach outlined above is adopted, allowing the conditional variance to be related to the variability of the macroeconomic factor, i.e. the debt/GDP ratio. This method appears to be most consistent with the intuition expressed by Tobin in his Nobel Lecture. In this respect the model is akin to the family of ARCH-M models with the main innovation being the replacement of the autoregressive errors by the variability of the macroeconomic factor.

\section{DATA DESCRIPTION AND EMPIR ICAL MODEL}

Data

The data set consists of nominal interest rates on 3-month Eurocurrency deposits on the London market and on 10year government bonds for five European countries: Italy, Germany, France, UK and Belgium. The rate of inflation for each country is calculated from the consumer price index. Germany is the benchmark country and the excess return for each country is calculated with respect to Germany. The data sample consists of quarterly data, covering the period from 1978:1 to 1996:4.

\section{Calculating real interest rates}

In order to implement an econometric model from the theory, the issue of evaluating the real ex-ante excess return needs to be addressed. Consistent with the existing literature on international finance we will assume that expectations are formed rationally (Engle and Rodrigues, 1989; 
Table 1. Unit root tests for inflation

\begin{tabular}{lll}
\hline & Augmented Dickey-Fuller & Phillips-Peron \\
\hline Germany & -1.67 & -3.26 \\
France & -1.04 & -1.76 \\
UK & -3.01 & -5.92 \\
Italy & -0.92 & -1.88 \\
Belgium & -1.44 & -2.74 \\
\hline
\end{tabular}

Thomas and Wickens, 1993). This allows the replacement of the ex-ante value by the realized ex-post real interest rate differential plus a forecast error. A further problem arises in calculating the real return on government bonds. When dealing with short period bonds, this calculation is straightforward. However, in the case of ten-year bonds it can be shown that the correct measure of the real interest rate is calculated by subtracting the average value of future expected inflation rates and the unobservable risk premium from the nominal rate (Cuthbertson, 1996; p. 224).

$$
r_{t}=R_{t}-\frac{1}{n} E_{t} \sum_{i=0}^{n-1} \Pi_{t+i+1}+\Phi_{t}^{n}
$$

In the empirical model, we calculate the real return ignoring the risk premium term, $\Phi_{t}$, but compensate for this by including the conditional variance (as a measure of the risk premium) as a regressor in the conditional mean equation of the model. As far as the value of future inflation is concerned the simplest way to generate these forecasts is to use an autoregressive model. However, formal tests show that the inflation series of each country in the analysis is an $\mathrm{I}(1)$ process (Table 1). Therefore, the best forecast of future inflation at each time horizon is the current inflation. Using this result in combination with the assumption of rational expectations we replace the average of expected future values of inflation with the current value and a forecast error.

Table 2 reports the main statistics for the relevant variables in the remainder of this analysis.

\section{The model}

We estimate the following model:

$$
\begin{aligned}
\left(r-r^{*}\right)_{t}= & \alpha_{0}+\alpha_{1} b_{t-i}+\alpha_{2} \Delta b_{t-i} \\
& +\alpha_{3} \sigma_{t-i}+\varepsilon_{t} \quad i=1,2 \\
\varepsilon_{t} \sim & N\left(0, \sigma_{t}^{2}\right) \\
\sigma_{t}^{2}= & \beta_{0}+\beta_{1}\left(b_{t-1}-\bar{b}\right)^{2}
\end{aligned}
$$

\begin{tabular}{|c|c|c|c|c|}
\hline & Mean & $\begin{array}{l}\text { Std } \\
\text { Deviation }\end{array}$ & Skewness & Kurtosis \\
\hline \multicolumn{5}{|l|}{ ITALY } \\
\hline Long Diff. & 0.37 & 3.64 & -0.67 & -1.37 \\
\hline Short Diff. & 1.95 & 3.67 & -0.26 & 4.71 \\
\hline Debt/GDP $(\%)$ & 82 & 22.8 & -0.02 & -1.30 \\
\hline \multicolumn{5}{|l|}{ BELGIUM } \\
\hline Long Diff. & 1.36 & 2.29 & 0.68 & 0.18 \\
\hline Short Diff. & 1.18 & 3.57 & -0.33 & 0.75 \\
\hline Debt/GDP( $\%)$ & 80.6 & 20.03 & -0.51 & -1.21 \\
\hline \multicolumn{5}{|l|}{ FRANCE } \\
\hline Long Diff. & 0.23 & 2.85 & -0.16 & 0.36 \\
\hline Short Diff. & 1.75 & 3.64 & 0.93 & 1.96 \\
\hline Debt/GDP( $\%)$ & 23.9 & 10.59 & 0.26 & -0.64 \\
\hline \multicolumn{5}{|l|}{ UK } \\
\hline Long Diff. & 0.20 & 4.37 & -0.43 & 2.97 \\
\hline Short Diff. & 1.25 & 4.12 & -0.89 & 1.59 \\
\hline Debt/GDP $(\%)$ & 16.39 & 4.56 & 1.16 & 1.52 \\
\hline
\end{tabular}

Table 2. Summary statistics for relevant variables

The model states that the error term in Equation 10 conditional on information available at time $t-1, \Omega_{t}$, is distributed normally with zero mean and variance $\sigma_{t}^{2}$. The second-order moment equation of the model seeks to explain the conditional heteroscedasticity using a macroeconomic variable as a potential driving force behind the conditional variance. In the empirical analysis, the Debt/ GDP ratio is chosen (as a proxy for domestic fiscal policy) as the factor driving the volatility of the term premium in interest rate differentials. Unlike Clare et al. (1993) who use shocks to macroeconomic variables to generate time-varying second moments and Engle and Rodrigues (1993) who consider the level of the variables, we propose to use the volatility of the macroeconomic factor to influence the conditional variance. For this purpose we employ a crude measure of Debt/GDP volatility defined as squared deviations from the mean.

In the following section we present the results of the estimated models using both short-term and long-term differentials.

\section{EMPIRICAL RESULTS OF THE MODEL}

The model is estimated as in Equation 10 including three lags of the Debt/GDP ratio and its change in the conditional mean equation. However, in the presentation of the results we report only the most significant lag. ${ }^{2}$

\footnotetext{
${ }^{2}$ A feature of both the short-term and long-term differential models is that the impact exerted by the Debt/GDP variable on the mean process does not occur with a uniform time lag. While the French differentials respond with a one period time lag, UK, Italy and Belgium require six months for the effect to feed through the system. This may be due to the quality of data used for the analysis.
} 


\section{The long term differential}

The parameter estimates of the long-term differential models are reported below. The $t$-statistics are reported in parentheses.

\section{ITALY}

$$
\begin{aligned}
\left(r-r^{*}\right)_{t} & =\underset{(-4.44)}{-9.28}+\underset{(4.05)}{0.09} b_{t-2}+\underset{(3.72)}{0.75} \Delta b_{t-2}+\underset{(1.84)}{0.55} \sigma_{t-1} \\
\sigma_{t}^{2} & =\underset{(1.77)}{0.84}+\underset{(4.46)}{0.02} s q b_{t-1}
\end{aligned}
$$

\section{FRANCE}

$$
\begin{aligned}
\left(r-r^{*}\right)_{t} & =\underset{(2.77)}{2.41}+\underset{(3.84)}{0.14} b_{t-1}+\underset{(2.44)}{0.39} \Delta b_{t-1} \\
\sigma_{t}^{2} & =\underset{(3.14)}{3.55}+\underset{(1.66)}{0.03} s q b_{t-1}
\end{aligned}
$$

\section{UK}

$$
\begin{aligned}
\left(r-r^{*}\right)_{t} & =\underset{(-2.05)}{-4.52}+\underset{(2.37)}{0.32} b_{t-2}+\underset{(1.94)}{0.62} \Delta b_{t-2} \\
\sigma_{t}^{2} & =\underset{(2.45)}{8.09}+\underset{(2.01)}{0.30} s q b_{t-1}
\end{aligned}
$$

\section{BELGIUM}

$$
\begin{aligned}
\left(r-r^{*}\right)_{t} & =\underset{(-1.86)}{2.53}+\underset{(2.34)}{0.04} b_{t-2}+\underset{(3.19)}{0.38} \Delta b_{t-2}+\underset{(1.52)}{0.18} \sigma_{t-1} \\
\sigma_{t}^{2} & =\underset{(1.28)}{0.94}+\underset{(2.61)}{0.01} s q b_{t-1}
\end{aligned}
$$

The results show that in all four cases the parameters $\alpha_{1}$ and $\alpha_{2}$ are statistically significant. This confirms the existence of both a short-run and long-run Debt/GDP impact on the risk premium in the real long interest rate differential. For countries with a high Debt/GDP ratio, like Italy and Belgium, the parameter $\alpha_{3}$ is also statistically significant. This may be evidence of financial markets' perceptions of the unsustainable fiscal position of these countries, requiring a higher risk premium to induce investors to hold their national debt instruments. In contrast, the $\alpha_{3}$ parameter is not significantly different from zero at the 5\% confidence level in the relatively low-debt countries such as France and UK. Furthermore we observe that for the high-debt countries the long-run impact exerts a weaker influence on the risk premium than in France or UK. This may be accounted for by the significance of the measure of riskness.

Interestingly the results confirm that the Debt/GDP ratio is a driving force behind the conditional variance of the process. The coefficients $\beta_{1}$ are found to be highly significant in the second moment equation for all countries. This result accentuates the existing link between the financial markets and the underlying macroeconomic factors. The actions of the fiscal authority in each country, in managing government debt, is proven to have an impact on both the mean and the volatility of the long-term real interest rate differential.

\section{The short-term differential}

The parameter estimates of the short-term differential models are reported below. The $t$-statistics are reported in parentheses.

$$
\begin{aligned}
\text { ITALY } \\
\left(r-r^{*}\right)_{t}=\underset{(0.99)}{1.77}+\underset{(0.20)}{0.003} b_{t-2}+\underset{(2.82)}{0.68} \Delta b_{t-2} \\
\sigma_{t}^{2}=\underset{(1.49)}{1.15}+\underset{(5.22)}{0.03} s q b_{t-1}
\end{aligned}
$$

\section{FRANCE}

$$
\begin{aligned}
&\left(r-r^{*}\right)_{t}= \underset{(-2.12)}{1.98}+\underset{(0.61)}{0.0004} b_{t-1}+\underset{(1.85)}{0.01} \Delta b_{t-1} \\
& \sigma_{t}^{2}=\underset{(2.50)}{4.04}+\underset{(3.53)}{0.001 s q b_{t-1}} \\
& \mathbf{U K} \\
&\left(r-r^{*}\right)_{t}=\underset{(0.66)}{1.34}+\underset{(0.21)}{0.03} b_{t-2}+\underset{(1.62)}{0.62} \Delta b_{t-2} \\
& \sigma_{t}^{2}=\underset{(3.02)}{8.34}+\underset{(2.03)}{0.25} s q b_{t-1}
\end{aligned}
$$

\section{UK}

$$
\begin{aligned}
\text { BELGIUM } \\
\left(r-r^{*}\right)_{t}=\underset{(0.26)}{0.34}+\underset{(0.59)}{0.01} b_{t-2}+\underset{(3.36)}{0.58} \Delta b_{t-2} \\
\sigma_{t}^{2}=\underset{(2.08)}{1.53}+\underset{(3.78)}{0.02} s q b_{t-1}
\end{aligned}
$$

The results show that the parameters $\alpha_{2}$ are statistically significant for all countries confirming the importance of the short-run dynamic effect on the short-term real interest rate differential. In contrast, the coefficients $\alpha_{1}$ and $\alpha_{3}$ are not significant, suggesting that neither the long-run impact of the Debt/GDP ratio nor the conditional volatility of the process exert an influence on the short-term differential. This is not surprising since it is unlikely that a rational investor would expect the government to renege on its debt over such a short investment horizon. As in the previous case the Debt/GDP ratio is found to be highly significant in the second-order moment equation for all countries.

\section{CONCLUDING REMARKS}

The aim of this paper was to examine the potential influence of domestic fiscal policy on the risk premium in the real interest rate differential between countries. Using Germany as the benchmark country, we conducted the analysis for both the short-term and long-term real interest rate differential of the main European countries. We 
estimated a model that allows macroeconomic factors to influence both the conditional first and second-order moments of the process.

For the long-term interest rate differential, the Debt/GDP ratio has both a short-run and long-run impact on the risk premium. For countries with a high Debt/GDP ratio, like Italy and Belgium, we find that a measure of the overall riskiness of the economy is also a significant explanatory variable for the level of the differential. In all cases, the volatility measure of the Debt/GDP ratio was found to be a statistically significant determinant of the conditional volatility of the process.

In the case of the short-term interest rate differential, it was found that only the short-run dynamic effect was important in determining the conditional mean of the process. In contrast, neither the long-run impact nor the measure of the riskiness was significant in the mean equation. Again the Debt/GDP volatility proved to be a significant variable in the conditional second-order moments.

All this empirical evidence strongly supports the importance of the Debt/GDP ratio as an explanatory variable for the risk premium. Its ability to influence both the first and secondorder moments of the real interest rate differential means that this variable deserves more attention than it has been previously afforded in the literature. From a policy point of view, this analysis supports the decision to include the Debt/ GDP ratio as one of the convergency criteria for monetary union set out in the Maastricht treaty. Without such a convergence, the risk premium could not be eliminated.

\section{ACKNOWLEDGEMENTS}

The authors acknowledge insightful comments from Mike Wickens, Charles Goodhart and Paul Masson and would like to thank participants at the VI Annual Finance Conference held in Università Tor Vergata, Rome on 20 November, 1997.

\section{REFER ENCES}

Bollerslev, T. (1986) A generalized autoregressive conditional heteroskedasticity, Journal of Econometrics, 31, 307-27.

Clare, A. D., O'Brien, R. Thomas, S. H. and Wickens, M. R. (1993) Macroeconomic shocks and the domestic CAPM: evidence from the UK stockmarket, University of York, working paper 94/10.

Constantinides, G. M. and Mallaris, A. G. (1995) Portfolio theory, in R.A. Jarrow, V. Maksimovic and W. T. Ziemba (eds), Handbook of Finance, North Holland.

Cuthbertson, K. (1996) Quantitative Financial Economics, John Wiley \& Sons.

Engle, C. and Rodrigues, A. P. (1989) Tests of international CAPM with time-varying covariances, Journal of Applied Econometrics, 4, 119-38.

Engle, C. and Rodrigues, A. P. (1993) Tests of mean-variance efficiency of international equity markets, Oxford Economic Papers, 45, 403-21.

Engle, R. F. (1982) Autoregressive conditional heteroskedasticity with estimates of the variance of $\mathrm{UK}$ inflation, Econometrica, 50, 987-1008.

Frankel, J. A. (1982) In search of the exchange risk premium: a six currency test assuming mean-variance optimisation, Journal of International Money and Finance, 1, 255-74.

Frankel, J. and MacArthur, A. (1988) Political versus currency premia in international real interest differentials: a study of forward rates for 24 countries, European Economic Review, 32, 1083-121.

Limosani, M. and Wickens, M. R. (1998) What explains real interest rate differentials across European countries? Further empirical analysis. Unpublished paper, University of York.

Markowitz, H. M. (1952) Portfolio Selection, Journal of Finance, 46, 469-77.

Thomas, S. H. and Wickens, M. R. (1993) An international CAPM for bonds and equities, Journal of International Money and Finance, 12, 390-412.

Tobin, J. (1958) Liquidity preference as behaviour towards risk, Review of Economic Studies, 25, 65-86.

Tobin, J. (1982) Money and finance in the macroeconomic process, Journal of Money Credit and Banking, 4, 171204. 